\title{
Describing the Health Service Delivery Network of an Urban Poor Area and a Rural Poor Area
}

\author{
Hilton Y. Lam, ${ }^{1}$ Roberto de Vera, ${ }^{2}$ Adovich S. Rivera, ${ }^{1}$ Tyrone Reden Sy, ${ }^{1}$ Kent Jason G. Cheng, ${ }^{1}$ \\ Daryl Byte Farrales, ${ }^{1}$ Jaifred Christian F. Lopez ${ }^{3}$ and Red Thaddeus DP. Miguel ${ }^{1}$ \\ ${ }^{1}$ Institute of Health Policy and Development Studies, National Institutes of Health, University of the Philippines Manila \\ ${ }^{2}$ School of Economics University of Asia and the Pacific, Philippines \\ ${ }^{3}$ College of Medicine, San Beda College, Manila, Philippines
}

\begin{abstract}
Objectives. This study aimed to assess the health workforce's service capacities within a health Service Delivery Network (SDN) of an urban poor and a rural poor setting.

Methods. This is a concurrent mixed-methods study implemented in Navotas and Masbate, an urban poor and a rural poor area, respectively. Health needs of the residents were assessed through records review, qualitative methods and a household survey. Health facilities in the identified SDN were assessed using the Service Availability and Readiness Assessment (SARA) tool. Training data of Human Resource for Health (HRH) were also obtained.
\end{abstract}

Results. SDN in the two areas are different in terms of formality where memoranda of agreement were prepared between Masbate facilities but not in Navotas. Health worker to population ratios were 12.1 per 10,000 in Navotas and 2.7 in Masbate, respectively. The primary care facilities in the two sites met the recommended level of trainings for health workers in obstetric care, immunization, childhood nutrition and tuberculosis. There was a lack of post-graduate training in non-communicable diseases in all facilities. Poverty and geography were significant factors affecting health service delivery.

Conclusion. In terms of human resources, both sites have limited number of health workers and the ratios fall far below WHO guideline. Recommendations include: Primary health care staff complement should be increased in the two SDNs. HHRDB should conduct a study to settle the issue of continuing medical education requirements that are not congruent with WHO recommendations. The SDNs should include the access of medicines and commodities by poor patients in private facilities during times of stock outs. Also, during stock outs or unavailability of government health personnel, transportation should be made available via the SDN to transport poor patients to private or nongovernment facilities with the needed personnel. The DOH and HHRDB should investigate innovative strategies for telehealth services that do not require continuous electricity, nor telephone or cellphone signal.

Key Words: access and quality of healthcare, Human resource for health (HRH), Service availability and readiness assessment (SARA), Service delivery network (SDN)

\section{INTRODUCTION}

Corresponding Author: Hilton Y. Lam, MHA, PhD Institute of Health Policy and Development Studies National Institutes of Health

University of the Philippines Manila

623 Pedro Gil Street, Ermita, Manila 1000 Philippines

Telefax: +6323543832

E-mail: hiltonyulam@gmail.com
Achieving good health outcomes nationally requires balancing control between national and local governments over resolving local health concerns. For the Philippines, the attempt to strike such a balance led to the devolution of health services through the Republic Act 7160, the Local Government Code of 1991. Prior to this, control and management of health services were centralized, and were under the direct responsibility of the Department of Health (DOH). ${ }^{1}$ The devolution empowered local government units (LGUs) to directly respond to local health needs, and limited the DOH's functions to policy making, technical 
assistance, health system performance monitoring, and advisory roles.

Despite the stated intention of devolution to directly address local health needs and promote community participation, the Philippine Health Systems Review ${ }^{2}$ reported that this has caused the general decline and unequal distribution of quality of health services due to wide variation across local governments in terms of resources and capacity to manage their local health systems. As a result of devolution, local health systems have become vulnerable to local politics, with crucial health system management decisions, such as personnel hiring, supplies procurement, construction of facilities and service provision being influenced by individual and collective political interests.

Consequently, these concerns have led to the relatively inferior quality of services in public health facilities, and have promoted health seeking behavior that bypasses primary health care providers and prefers treatment in tertiary or highly specialized hospitals, even for simple cases that would ordinarily be treatable in primary care facilities. This phenomenon, a result of an unaddressed clamor for efficiency and quality in local health service delivery, has caused difficulties in the referral system, and often results in the overcrowding of higher level government hospitals.

Devolution has also impacted on the healthcare workforce in the Philippines, as shown by the Philippine Human Resources for Health Country Profile, published by the World Health Organization (WHO), ${ }^{3}$ in collaboration with the DOH Health Human Resource Development Bureau (HHRDB). It highlighted three significant issues in the recruitment and deployment of human resources for health (HRH) in local governments: 1) the uneven distribution of health workers; 2) the lack of regular LGU positions; 3) low salaries; and 4) irregular labor practices in LGUs related to local political interests, such as staffing people with insufficient professional training but with known political affinity with the ruling party, and hiring several contractual health workers who serve coterminus with the local chief executive who hired them. It points out that, since the establishment of the HRH network in 2006, there have been attempts to rationalize and harmonize policies in deploying health workers, with little success.

The Pan-American Health Organization (PAHO), in its "Assessment from Integrated Health Service Delivery Networks: Concepts, Policy Options and a Road Map for Implementation in the Americas" identified the use of integrated health service delivery network (SDN) as a means to expand primary health care within decentralized settings. Similarly, the DOH has also identified the opportunity to strengthen the weaknesses of devolved health centers and hospitals within a service delivery network (SDN) of private, public and civil society institutions (i.e., NGOs and faith-based), specially for poor and marginalized communities.

\section{OBJECTIVES}

Because of the need to develop such SDN arrangements, this study therefore aimed to describe the utilization and health workforce service capacities of SDNs within an urban poor and a rural poor setting. Specifically, this research aimed: (1) to determine the health service needs of two types of marginalized population in: (a) an urban area - urban poor and (b) a geographically isolated and disadvantaged areas (GIDA) - rural poor; (2) to describe the interplay among providers in an SDN; (3) to describe the health workforce's service capacities within the SDN (from public and private sectors) against health service needs of the foregoing marginalized population segments; (4) to identify the social, political, economic, and other related factors that affect the service capacity of the SDN (private clinics, independent practitioners); and (5) to recommend mechanism/s to strengthen health service delivery, especially those that are directed to poor marginalized women within an SDN.

\section{MATERIALS AND METHODS}

This study was given ethical clearance by the University of the Philippines Manila Research Ethics Board. This was a concurrent mixed-methods study in which health needs and health utilization of the study sites residents were assessed through household surveys and focus group discussions (FGDs) or key informant interviews (KIIs) with health providers. Health facilities in the health SDNs were assessed through records review, FGDs or KIIs with health providers, and the implementation of the WHO's Service Availability and Readiness Assessment (SARA) on each health facility of the SDN. The SARA measures service capacity of the facility on various service and infrastructural capacity indicators and on how the facility responds to the health service needs of the population. The SARA questionnaire was modified to be sensitive to the leading causes of morbidity and mortality of the areas. Questions on training of health workers were also added. The creators of the SARA tool allowed users to make necessary modifications on the tools. ${ }^{5}$ Triangulation of multiple data sources were employed.

Barangay (Brgy) Navotas East, Navotas City, Metro Manila was identified as the urban poor area; it has a total population of 22,425 as of $2014 .^{6}$ It is in the center of 14 barangays and considered to be the physical center of Navotas City. On the other hand, the rural poor area is Brgy Naro, an island barangay that is roughly about six to seven kilometers south-west of mainland Cawayan, Masbate. As per DOH definitions, Naro is a geographically isolated and disadvantaged area (GIDA). It has a total population of 3,352 as of $2014 .^{7}$ 


\section{RESULTS}

One hundred (100) respondents were sampled per barangay through systematic random sampling. Most of the respondents were female (Figures 1 and 2), with mean age of 43 years for Navotas East respondents, and 42 years for Naro respondents (Table 1). Most respondents in Naro had a monthly income of less than P5,000, while most in Navotas East had monthly income of PhP 8,000 to PhP 15,000. Respondents' houses in Naro were made mostly of temporary materials and most did not have their own toilets while

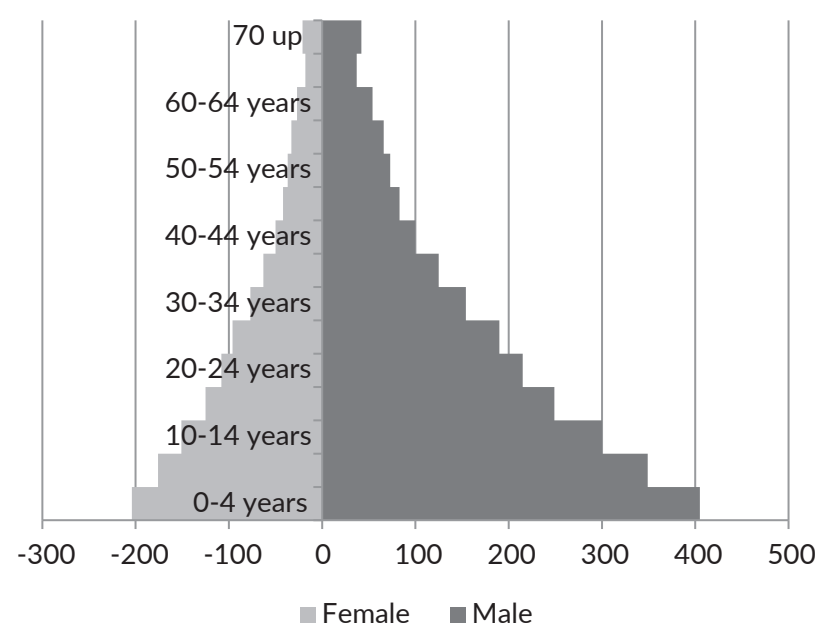

Figure 1. Age pyramid of Barangay Navotas East, Navotas City.

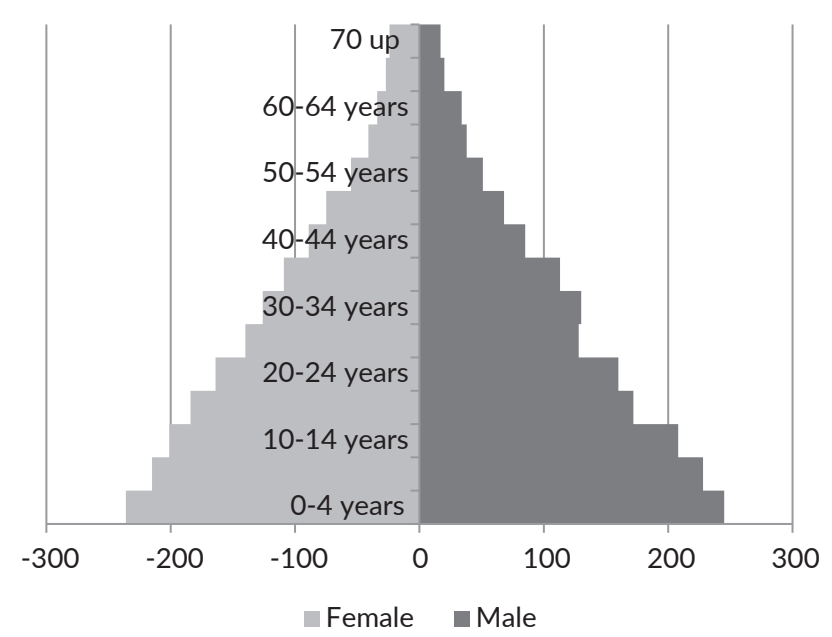

Figure 2. Age pyramid of Barangay Naro, Cawayan, Masbate.

Table 1. Age distribution of respondents

\begin{tabular}{ccc}
\hline & Navotas East & Naro, Masbate \\
\hline Mean & $43 \mathrm{y} / \mathrm{o}$ & $42 \mathrm{y} / \mathrm{o}$ \\
Median & $40 \mathrm{y} / \mathrm{o}$ & $42 \mathrm{y} / \mathrm{o}$ \\
Youngest & $18 \mathrm{y} / \mathrm{o}$ & $19 \mathrm{y} / \mathrm{o}$ \\
Oldest & $83 \mathrm{y} / \mathrm{o}$ & $85 \mathrm{y} / \mathrm{o}$ \\
\hline
\end{tabular}

respondents in Navotas East were mostly made of semipermanent materials and had their own toilets. For the FGD and KIIs, 20 health professionals participated. On the other hand, four health facilities per barangay were assessed using the SARA tool.

\section{Health needs and health service utilization}

The Navotas East health center is served by the Bagumbayan Health Center. In Naro, there is a barangay health station (BHS) with a midwife on duty but the nearest health center is the Cawayan Rural Health Unit, which is approximately $25 \mathrm{~km}$ away, and traversable by boat only. The health workers from the barangay health center (BHC) and the rural health unit (RHU), respectively, were interviewed. Health workers from Navotas East reported that the top health needs of their residents related to (1) upper respiratory tract infection, (2) teen pregnancy, (3) family planning, and (4) tuberculosis, while health service providers in Brgy Naro said that the top health needs of their residents related to (1) maternal health, (2) lack of vitamins among children, (3) malnutrition, and (4) stillbirth. The Navotas East's BHC and Naro's BHS records revealed that respiratory tract infection and hypertension were the most common causes of morbidity in both areas while cerebrovascular accidents were the most common cause of mortality in both areas. Both Navotas East and Naro households were asked to enumerate their felt health needs, and they mentioned provision of vitamins, medicines, and vaccines, as well as free checkups and laboratory examinations. Table 2 summarizes the health needs.

Table 2. Health needs of Navotas East and Naro residents

\begin{tabular}{|c|c|}
\hline Navotas East & Naro \\
\hline \multicolumn{2}{|c|}{ Health needs identified by the community } \\
\hline \multicolumn{2}{|c|}{$\begin{array}{l}\text { Vitamins/Medicines/Vaccines Needed, } \\
\text { Free Check-up and Laboratory Needed, Hygiene Needs, } \\
\text { Schooling of Children, Emotional Needs of Children, } \\
\text { Nutrition Needs, }{ }^{*} \text { Vaccination of Children* }\end{array}$} \\
\hline \multicolumn{2}{|c|}{ Top morbidities } \\
\hline 1. Upper respiratory tract infection & 1. Acute respiratory infection \\
\hline 2. Hypertension & 2. Hypertension \\
\hline 3. Scabies & 3. Diarrhea \\
\hline 4. Dental caries & 4. Diabetes mellitus \\
\hline 5. Furuncle & 5. Punctured wound \\
\hline \multicolumn{2}{|c|}{ Top mortalities } \\
\hline 1. Cerebrovascular accident & 1. Cerebrovascular accident \\
\hline 2. Cancer (liver and lung) & 2. Fetal death \\
\hline 3. Cardiovascular disease (CVD) & 3. Pneumonia \\
\hline 4. Pneumonia & 4. All forms of cancer \\
\hline & 5. Multiple gunshot wound \\
\hline
\end{tabular}

Note: * Cited only by Naro respondents. Top morbidities and mortalities are sourced from barangay health records.

The household survey revealed a situation similar with those reported in FGDs and records. The common conditions they experienced in the past 12 months were mostly acute illnesses such as fever, cough, colds, and diarrhea and about $25 \%$ experienced nutrition-related illness and non- 
communicable diseases. Possible respiratory tract infections like cough and colds that do not last for more than a week and slight fever had the highest incidence among survey respondents in both areas. However, only $70.59 \%$ and $62.63 \%$ consulted for cough and colds in the health centers for Navotas East and Naro, respectively. Of those who had fever, only $46.84 \%$ and $27.08 \%$ consulted in the health center for Navotas East and Naro, respectively. In terms of primary health care services, on average only $44.1 \%$ of Navotas East residents and $32.9 \%$ of Naro residents actually accessed these BHC and RHU services, despite their articulated felt need. It is interesting to note that a higher proportion of the rural GIDA community feel a greater need for family planning services compared to the urban poor community.

\section{Describing the health SDNs}

Figure 3 shows the map of the two barangays. In Navotas East, aside from the Bagumbayan Health Center, there is a private polyclinic and a lying-in clinic nearby. The Navotas City Hospital which has 50 authorized bed capacity ${ }^{8}$ has yet to be opened during the study period. In Naro, there is a BHS and the privately-operated Condor Lying-in Clinic within the barangay but the RHU and the Cawayan District Hospital which has 10 authorized bed capacity are only accessible via a boat ride to the main island of Cawayan.

Service delivery network in the two areas are different in terms of formality. Cawayan District Hospital in Naro has a Memorandum of Agreement with Condor lying-in private health facility. No such formal agreements were present in Navotas East.

Navotas East BHC employees identified four medical facilities, within a radius of $2.7 \mathrm{~km}$ to $12.7 \mathrm{~km}$ where they refer cases to if they have no infrastructural or manpower capacity to treat them. For Naro, four referral medical facilities can be found within a radius of $1.2 \mathrm{~km}$ to $200 \mathrm{~km}$.

Based on the household survey, respondents in both areas preferred to consult in the barangay facilities for most

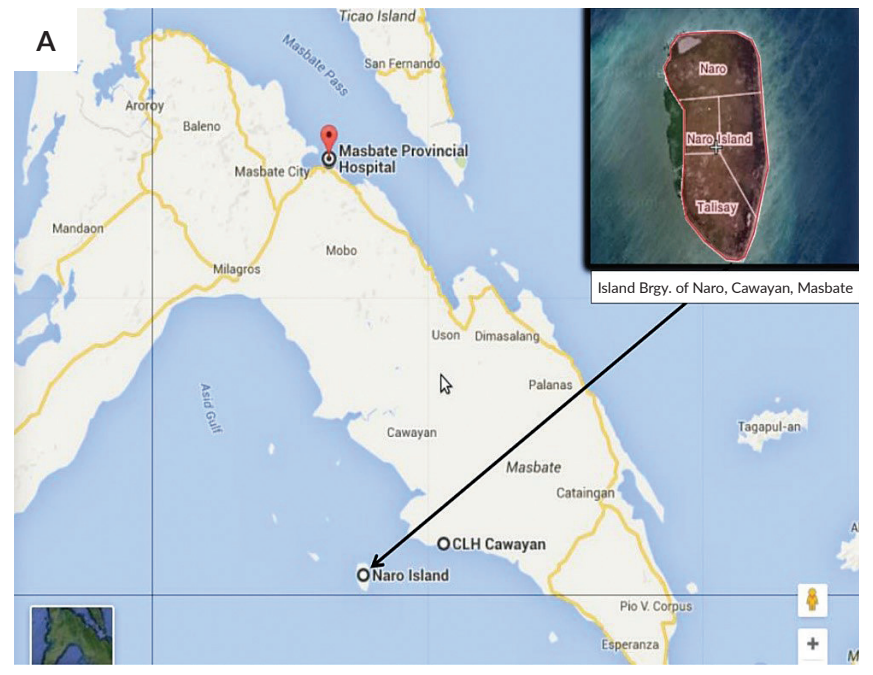

symptoms and conditions. In Navotas East, there were some conditions that were preferentially consulted in facilities outside of Navotas. These included emergencies such as pneumonia, febrile and epileptic seizures, heart attack and stroke, and non-emergent conditions such as diabetes and drug addiction. For Naro, only two conditions were preferentially consulted in the district hospital over the barangay facility: trauma and diarrhea with vomiting. Myocardial infarction was preferentially consulted in a private facility.

\section{The service capacity of the HRH in the health SDNs}

In Navotas, there were 169 health workers including 30 barangay health workers (BHWs) while in Masbate the number was 219 including $108 \mathrm{BHW}$. This gives a ratio of 12.1 health workers per 10,000 population in the Navotas SDN, and 2.7 per 10,000 in Cawayan, Masbate SDN. Cluster populations were used versus barangay populations since these facilities did not solely cater to the study barangays. In Navotas East, the BHC comprised of 1 medical doctor (MD), 3 nurses, 2 midwives, and 30 BHWs. The RHU only had 1 midwife, 1 nurse, and 1 BHW in Naro. Specialist physicians were available in the three higher level public facilities near Navotas East. However, Naro residents can only access specialists in private facilities in the capital town of Masbate, an hour of boat ride away from Naro. Table 2 shows the additional health workers needed given the current health-worker-to-population ratios.

Not all facilities included provided training data. The SARA approach was used in which facilities were assessed based on the availability of at least one trained health worker for each needed service. Although the SARA defines trained personnel as a person receiving training within two years, the DOH does not. Therefore, the results of ever trained, trained within past five years, and trained within the past two years are presented in Table 4.

In the qualitative interviews, health worker respondents in both sites lamented the inadequate number of health staff

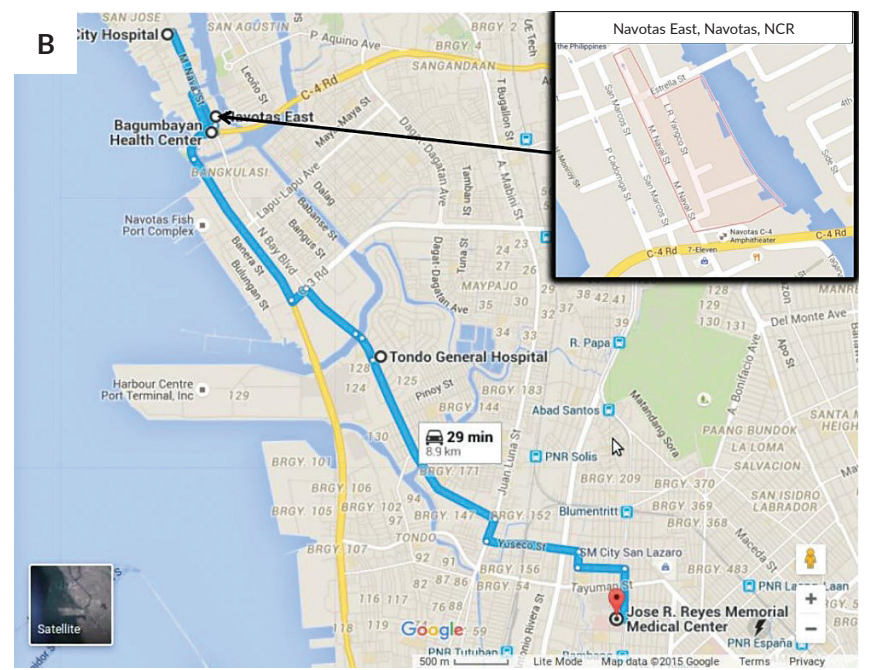

Figure 3. Map of the study sites. (A) Naro, Masbate. (B) Navotas East. 
Table 3. Health worker to population ratios

\begin{tabular}{|c|c|c|c|c|c|c|c|c|c|c|}
\hline \multirow{2}{*}{ Area } & \multirow{2}{*}{ Population } & \multicolumn{4}{|c|}{ Count } & \multicolumn{4}{|c|}{ Ratio per 10,000 population } & \multirow{2}{*}{$\begin{array}{l}\text { Additional number } \\
\text { of } \mathrm{HW} \text { needed }\end{array}$} \\
\hline & & MD & RN & MW & Any & MD & RN & MW & Any & \\
\hline Naro only & 3,352 & 0 & 0 & 1 & 1 & 0 & 0 & 2.98 & 2.98 & 7 \\
\hline Cawayan, Masbate & 63,115 & & & & & & & & & \\
\hline Government only & & 3 & 23 & 21 & 47 & 0.48 & 3.6 & 3.3 & 7.45 & 97 \\
\hline Private + Government & & 32 & 45 & 23 & 100 & 5.1 & 7.1 & 3.6 & 15.8 & 44 \\
\hline Navotas Bagumbayan Cluster & $18,151^{*}$ & 1 & 3 & 2 & 6 & 0.06 & 0.17 & 0.11 & 0.33 & 36 \\
\hline Navotas East Brgy & 2,245 & 1 & 3 & 2 & 6 & 0.45 & 1.3 & 0.89 & 2.67 & $\mathrm{n} / \mathrm{a}$ \\
\hline
\end{tabular}

MD - medical doctor, $R N$ - nurse, MW - midwife, $H W$ - health worker

* Population estimated using National Statistics Office data and growth rates.

Table 4. Trainings received by primary health care facilities staff

\begin{tabular}{|c|c|c|c|c|}
\hline \multirow{2}{*}{ Services } & \multicolumn{2}{|c|}{ Navotas East } & \multicolumn{2}{|c|}{ NARO } \\
\hline & BHS & LI & BHS & RHU \\
\hline Antenatal care & $\wedge$ & $*$ & $*$ & $Y$ \\
\hline Basic obstetric and neonatal care & Y & $\wedge$ & * & Y \\
\hline Family planning & & & * & \\
\hline Childhood Immunization & Y & $\wedge$ & $*$ & Y \\
\hline Child health care services & $\wedge$ & & * & $*$ \\
\hline $\begin{array}{l}\text { Garantisadong pambata and } \\
\text { childhood nutrition }\end{array}$ & Y & & $\wedge$ & Y \\
\hline Tuberculosis & Y & $*$ & $*$ & Y \\
\hline Non-communicable diseases & & & & \\
\hline HIV/AIDS related & Y & & & \\
\hline Emergency care and life support & $*$ & $*$ & $\wedge$ & * \\
\hline Trained within 2 years & $50 \%$ & $0 \%$ & $0 \%$ & $50 \%$ \\
\hline Trained within 5 years & $60 \%$ & $30 \%$ & $60 \%$ & $70 \%$ \\
\hline Trained more than 5 years ago & $80 \%$ & $50 \%$ & $80 \%$ & $70 \%$ \\
\hline
\end{tabular}

$\wedge$ - received training more than 5 years ago, ${ }^{*}$ - received training in past 5 years, $Y$ - received training in the last 2 years; $B H S$ - barangay health station, $\mathrm{RHU}$ - rural health unit, $\mathrm{LI}$ - lying-in

and the feeling of being overworked in their primary health care facilities. Methods to replenish the roster of health workers were also ambiguous and subject to political factors.
While the trainings had the goal of enhancing the service capacity of the personnel, these had the unintended effect of creating backlogs in other service areas, especially when the trainings were held off-sites and the health workers were asked to leave from their places of assignment.

\section{Service readiness of health facilities}

The SARA has a pre-set list of tracer items per service that will be assessed for their availability. Percentages are therefore computed to summarize the state of the facility's capacity to render specific services. For example, to assess the service of STI treatment, five specific tracer items are listed, i.e., syphilis rapid test, male condoms, metronidazole, ciprofloxacin, and ceftriaxone injection. So, if a facility has 2 of these 5 items, the facility is assessed to have a $2 / 5=40 \%$ readiness for STI treatment. For a network, the availability of the item in one facility makes up for the unavailability of that item in another facility. So, in an SDN with 3 facilities, if one facility scored $100 \%$, the network will score $100 \%$ no matter what scores the other two facilities obtained. The availability of services is shown in Table 5.

Table 5. Availability of services in the health facilities

\begin{tabular}{|c|c|c|c|c|c|c|c|c|c|c|}
\hline \multirow{2}{*}{ Services } & \multicolumn{5}{|c|}{ Navotas East } & \multicolumn{5}{|c|}{ Naro } \\
\hline & BHS & LI & $\mathrm{CH}$ & PP & SDN & BHS & RHU & DH & PH & SDN \\
\hline Operating hours per day & $8^{a}$ & 24 & 24 & 24 & $\mathrm{Y}$ & 8 & 24 & 24 & 24 & $\mathrm{Y}$ \\
\hline Antenatal care & $\mathrm{Y}$ & $\mathrm{Y}$ & $\mathrm{Y}$ & $\mathrm{Y}$ & $\mathrm{Y}$ & Y & $\mathrm{Y}$ & $\mathrm{Y}$ & $\mathrm{Y}$ & $\mathrm{Y}$ \\
\hline OB and NB care & & $\mathrm{Y}$ & Y & Y & $\mathrm{Y}$ & Y & $\mathrm{Y}$ & $\mathrm{Y}$ & $\mathrm{Y}$ & $Y$ \\
\hline Caesarean section & & & Y & & $\mathrm{Y}$ & & & & & $\mathrm{Y}$ \\
\hline Child Immunization & Y & & & Y & Y & $Y$ & $Y$ & & $Y$ & $\mathrm{Y}$ \\
\hline Child Health & Y & $\mathrm{Y}$ & & Y & Y & Y & Y & $\mathrm{Y}$ & Y & $\mathrm{Y}$ \\
\hline HIV testing & Y & & & & $\mathrm{Y}$ & & $\mathrm{Y}$ & & Y & $\mathrm{Y}$ \\
\hline STI services & Y & & & & Y & & & & Y & $\mathrm{Y}$ \\
\hline TB services & Y & & & & Y & & Y & & Y & $\mathrm{Y}$ \\
\hline NCD services & Y & Y & Y & Y & $\mathrm{Y}$ & Y & Y & Y & Y & $\mathrm{Y}$ \\
\hline Surgical services & & & Y & & Y & & & $\mathrm{Y}$ & $\mathrm{Y}$ & $\mathrm{Y}$ \\
\hline Blood transfusion & & & Y & & Y & & & & Y & Y \\
\hline Diagnostics & Y & Y & Y & Y & Y & & & Y & Y & $\mathrm{Y}$ \\
\hline Medicine dispensing & Y & & Y & & Y & $\mathrm{Y}$ & $\mathrm{Y}$ & Y & $\mathrm{Y}$ & $\mathrm{Y}$ \\
\hline Ambulance & & & $\mathrm{Y}$ & $\mathrm{Y}$ & $\mathrm{Y}$ & b & $\mathrm{Y}$ & $\mathrm{Y}$ & $\mathrm{Y}$ & $\mathrm{Y}$ \\
\hline Scores & $64 \%$ & $36 \%$ & $64 \%$ & $50 \%$ & $100 \%$ & $50 \%$ & $64 \%$ & $57 \%$ & $93 \%$ & $100 \%$ \\
\hline
\end{tabular}

Footnotes: ${ }^{a}$ Midwife is on-call 24 hours for emergencies and deliveries. ${ }^{b}$ Sea ambulance available but was not functional at time of visit.

Cells that are blank mean that the facility reported that they do not have this service while $Y$ means, the service is available. Services in bold represent services which correspond to a need by the community either felt or as reflected in their health statistics.

BHS - barangay health station, RHU - rural health unit, PH - private health facility, DH - district hospital, LI - lying-in, PP - private polyclinic, $\mathrm{CH}$ - city hospital 
All hospitals had $80 \%$ or higher readiness scores in terms of equipment in both areas. In terms of diagnostic capacity, Navotas facilities had higher readiness scores compared to Masbate with three of four assessed facilities having 0 readiness scores. Navotas facilities also had higher scores than Masbate in terms of essential medicines. A network score was computed by determining if at least one facility had one item or test in the list. Both SDNs scored 100\% readiness for basic equipment and diagnostic tests. In terms of essential medicine, Masbate scored 76\% while Navotas scored 84\%.

The SARA scores suggest varying readiness in the provision of services which is reflected in the qualitative interviews. In Naro, the lack of proper infrastructure and equipment had affected their provision of services such as those done at night. The lack of computers was also mentioned as a hindrance in performing their reporting function. Inconsistency in the delivery schedule of medicines was also reported as impediments to effective delivery of health services in Navotas. Health facilities' financial capacity was also hampered by delays in PhilHealth reimbursements. Table 5 summarizes the availability of services in the health facilities.

\section{DISCUSSION}

Universal Health Care is one of the main guarantees of the Philippine Health Agenda under the Duterte administration..$^{10}$ One of the strategic goals of this program is to improve the access to and the quality of public hospitals and health facilities, including Service Delivery Networks (SDN).

The average household in Navotas East and Naro ranked health as $4^{\text {th }}$ and $7^{\text {th }}$ in their priority of needs, respectively. Health expenses comprised roughly $8-9 \%$ of the average households' expenditure. When asked to identify general and specific to women's and children's health needs, households from both Masbate and Navotas enumerated the following common themes: aside from publicly-provided (or freely provided) specific curative and preventive health services and health commodities (e.g., drugs, vitamins, vaccines), they also stated basic sanitation and financial support. Unique to identified health needs for children is deworming and the addition of dietary needs, emotional needs, and education subsets. Prenatal check-ups, reproductive health education, and women-specific laboratory services such as pap smears and health commodities such as anti-cervical cancer vaccines and contraceptives were also mentioned which may be attributable to the predominance of women among respondents. Women's health needs were closely related to family planning service needs.

Results from their responses and documents review showed that disease patterns in both communities seemed to be reflective of the national trend where acute conditions dominated the list of morbidities, followed by a few cases of non-communicable conditions and injuries due to trauma. In terms of primary health care services, on average only $44.1 \%$ of Navotas East residents and 32.9\% of Naro residents accessed these RHU and BHS services, despite their articulated felt need for such. This may be due to accessibility issues arising from various reasons such as geography and financial barriers although there were other possible explanations for this observation. Low utilization may be due to low seeking behavior for preventive health care suggesting low value put by individuals on preventive services. It could also be that respondents utilize these services in other facilities such as private clinics or hospitals suggesting low trust for services offered by these government facilities. These other explanations imply the need to promote health seeking behavior as well as improve the reputation of government facilities. There might also be a need to inspect facilities in terms of user satisfaction and quality of services.

The reliance of the two communities on government public health facilities for many of their health needs, especially preventive health services like immunization and maternal care, was high. BHSs and RHUs included in the study can provide the primary health needs of the community. But for emergency conditions, Navotas East respondents chose to go directly to hospitals outside their city such as Manila. There was also a proportion of Navotas East respondents who preferred private practitioners for their illnesses, regardless of condition. In Naro, the referral between RHU and district hospital was formalized through a MOA but this was not the case in Navotas East. This means patients who are referred out for further care are not assured of acceptance in the higherlevel facilities. To protect the patients, referral systems should then be formalized through MOAs or contracts.

Based on the WHO benchmark of 23 health workers per 10,000 population ${ }^{11}$ as the minimum ratio for providing adequate immunization and antenatal care coverage, Naro SDN needs to have 7 more health workers while the Navotas SDN would need 36 more health workers. Because of this insufficient number of health service providers, it is therefore not surprising that only $44.1 \%$ of Navotas East residents and $32.9 \%$ of Naro residents were given primary health care services. In addition, respondents also noticed the understaffing at the BHSs/ RHUs, and that they preferred to access care in private hospitals. The deficiency of HRH seemed to be more apparent in Naro since Naro failed to meet local standard of one midwife per barangay given that the lone midwife of Naro handled two BHSs and four barangays in the island.

In terms of the trainings of the available staff, almost all had at least one health worker who received training at least once, except for trainings pertaining to non-communicable diseases. Doctors with specialty training were also available in the facilities which catered to the two sites although not necessarily located within the barangays themselves. A limitation of this assessment is that it assumes having just one trained individual is enough for a facility presumably because knowledge sharing and diffusion will occur. It was 
noted that there were no local data or $\mathrm{DOH}$ requirement on a standard regarding the frequency of training and updates that public health workers should receive. Although, based on the qualitative data, there is a need to review the required minimum number and schedule of trainings as they can interrupt service provision, given the current insufficient numbers of health service providers within the SDNs.

Given these gaps in the availability and training of health workers in the government side, utilization of the private sector (either not-for-profit or for-profit organizations) in the delivery network should be explored. Gaps that could be addressed by the network approach include noncommunicable disease services, surgical and diagnostic services. Experiences in out-sourcing services to private facilities have been documented and show that quality of services is usually at par and performance equivalent to government facilities. ${ }^{12}$

Socio-economic and political factors widen the gap between the service capacities of the HRHs and the demand of healthcare and health commodities. As identified in the FGDs with stakeholders and health workers, poverty remains one of the major societal and economic problems that renders even free healthcare inaccessible. Poverty is this multifaceted societal dilemma the national government must address since it renders poor people without opportunities to achieve optimal health, to complete education, to find desired jobs, et cetera. While basic healthcare is freely provided mainly by the government and secondarily by charitable institutions, poor families may not be able to cover for the cost of transporting the patient to the health facility. To this end, the SDN may consider including agreements on use of private transport to convey poor patients from their residences to the appropriate facilities and vice-versa.

The devolution of the healthcare functions from the national government has negative effects on the staffing of public health facilities as observed in the study sites. Thus, healthcare provision is dependent on the priorities of local governments. In the two SDNs, many health-worker positions have yet to be filled and based from the FGD, health workers perceived that nepotism was present in hiring decisions. Further, winning politicians would give nonitemed positions to their supporters, instead of filling up itemed positions with qualified health workers, because this is an easy way to reward their political supporters as nonitem positions usually do not require similar technical rigors as itemed positions. Several local government politicians allegedly co-op health services and commodities that are freely provided by the national government by packaging them into becoming their election campaign materials.

Users' perception of public health facilities also plays a major role in affecting health-seeking behavior. While services are mostly free, medicines and health workers are perceived to be not readily available. Availability of supplies, equipment, and medications would affect service provision. In the two sites, low scores in service capacities such as family planning would prevent providers in being able to give it to the community members. Lack of medications or laboratory supplies lead to patient dissatisfaction. Thus, the healing regimen is incomplete in the absence of needed drugs supplies. DOH must then ensure that the supply chain of drugs and other health commodities is ever-present, and need to augment the health workforce in the primary care level in the SDNs. Formalizing the SDN, and including more facilities may be one method in which the $\mathrm{DOH}$ can help the LGUs meet their health workforce and medicines and commodities shortfall, without letting the LGUs "off-thehook" so to speak.

This study has the following limitations: First, because this study is the first to describe the SDNs of Naro and Navotas, the results are not powered to be generalizable to the rest of the Philippines. Second, not all health facilities considered as part of Navotas East and Naro health SDN were evaluated using the revised version of the SARA tool because several health facilities refused to participate and some cannot be reached during the time of the data collection; nevertheless, at least $75 \%$ of the facilities in the SDN participated. Third, for the assessment of the training, regular employees were not distinguished from contractual employees because available data for some facilities are also not suitable for disaggregation.

\section{CONCLUSION}

Using multiple methods, the needs of two SDNs were described. Although the list of common health illnesses and conditions were fairly consistent based on secondary data, key informant interview, and household survey, elicited felt needs for services were a bit different for each method. Readiness scores of health facilities vary for each service. In general, the lowest level facilities in the two sites have low scores except for check-up for children in Naro and maternal, nutrition and immunization services in Navotas East. Limitations in the government facilities have prompted referrals to facilities outside the sites with varying level of formality. Although in general, residents would still opt to consult mainly in the barangay level facilities for acute and non-emergency complaints, many seek emergency care in private facilities within Naro, and Navotas East, and seek tertiary care outside of Naro, and Navotas East. In terms of human resources, both sites have limited number of health workers and the ratios fall far below WHO guideline. This is backed up by suggestions in the household survey to add additional staff in their facilities and by the health workers themselves complaining of being overworked. In terms of post-graduate training, the two SDNs have recently trained staff on maternal and child health, tuberculosis, and nutrition but lack training in skin diseases, non-communicable diseases, and family planning. Political and cultural factors also play a role in the ability of health workers to perform their duties through various mechanisms such as decreasing health seeking behavior, hindrance in the 
hiring of human resources, and procuring supplies for their facilities. The need to attend trainings outside of their areas was highlighted as a factor that affects service delivery due to the fact that there is no one to substitute for them.

\section{RECOMMENDATIONS}

Even as this paper is a case study of two areas, the generalizability of the insights gained may need to be confirmed with more studies in the future. Nevertheless, there is strong indication within the two SDNs for the following:

Primary health care staff complement should be increased in the SDN. As the de facto gatekeepers in the SDN, the burden of primary health care belongs to the RHUs and BHSs. Using the WHO standard, Naro needs 44 additional primary health care workers, while Navotas East would need 36 additional health workers. Although DOH standards do not require the 2-year continuing education of $\mathrm{WHO}$, the current primary healthcare worker complement is so limited that when one leaves for a training, or falls sick, there is no substitute.

To settle the ambiguity of whether $\mathrm{DOH}$ should follow the WHO standard on training (i.e., continuing education), HHRDB should conduct a study to settle this issue, on whether or not to accept the bi-annual updates. The $\mathrm{DOH}$ Academy, as the intended training arm of the HHRDB should be engaged deeply in this discussion.

Complete healthcare can only be achieved not only with service but also with health commodity provision. Thus, the DOH must ensure a fully functional supply chain of medicines, vitamins, vaccines, and other health supplies which minimizes or is entirely absent of stock outs. The SDN should include the access of medicines and commodities by poor patients in private facilities during times of stock outs. Also, during stock outs or unavailability of government health personnel, transportation should be made available via the SDN to transport poor patients to private or nongovernment facilities with the needed personnel. In this situation, the private facilities should agree to not charge the patient, but instead, charge the RHU or the government facility experiencing the stock out or non-availability of personnel.

While the PAHO and WHO recommend the use of telehealth to augment the limited service capacities of underserved areas, the case of these two GIDA SDNs highlights the infrastructure problem of unreliable electricity, telephone service, and cellphone network. Therefore, the $\mathrm{DOH}$ and HHRDB should investigate innovative strategies for telehealth services that do not require continuous electricity, nor telephone or cellphone signal, such as solar powered, asynchronous telemedicine modules like YouTube videos, podcasts and others.

Allow the Government facility to be able to pay private facilities within the SDN for nontraditional services such as ambulance transport (even to those who do not abide by the no balance billing policy of PhilHealth), feeding programs, or wellness trainings, to meet some of the feltneeds for primary health care, as stated by households.

There seems to be de facto evidence that the $\mathrm{DOH}$ can turn to SDN to quickly augment the under-provision of public health services, with minimal disruption in the daily lives of poor patients, so that the poor will be served comprehensively. As such, the DOH should consider investing in SDNs, specifically in:

1. Crafting health situational analyses specific for each SDN to serve as the basis for all SDN goals and activities. Currently, health records and statistics are scattered and stored separately and independently, so that it may require the direct and deliberate leadership of DOH through HHRDB to collect, collate, analyze, and produce SDN specific health situational analyses.

2. Identifying financial and nonfinancial incentives for integration such that SDN residents will not feel as if they are choosing one facility over another (i.e., private hospital over government hospital), instead they will feel that the facilities are part of one network. And ultimately, insisting that all SDNs be created with formal MOA or contracts with the $\mathrm{DOH}$ either as a contracting party or an active advisor.

3. Creating an integrated system for SDN to achieve interfacility communication, patient transport, procumbent of supplies, patient record keeping, and sharing of patient results of laboratory, radiology, pathology, and blood banking services. This may require the HHDRB to purposely engage and consult with the DOH's information management system, and knowledge management systems, so that there would be congruent and coordinated development.

\section{Acknowledgments}

The authors gratefully acknowledge the funding support of the Philippine Department of Health, through the research management mechanism of the Philippine Council for Health Research and Development; the expertise of Dr Grace Marie Ku and Dr Lotgarda Tayao; the research assistance of Jesebell de Jesus; the data collection services of Jamila Carreon, Jojana Christine General, Joana Glenda Magalad, Taurean Magallanes, and May Ann Malong; and the health workers and study participants for their support to this project.

\section{Statement of Authorship}

All authors have approved the final version submitted.

\section{Author Disclosure}

All the authors declared no conflicts of interest.

\section{Funding Source}

This paper was funded by the Department of Health through the Philippine Council for Health Research and Development. 


\section{REFERENCES}

1. Republic of the Philippines. Republic Act 7160. Local Government Code. 1991.

2. World Health Organization. Philippine Health Systems Review [Online]. 2011 [Accessed 12 Feb 2015]. Available from http:// www.wpro.who.int/philippines/areas/health_systems/financing/ philippines_health_system_review.pdf.

3. Department of Health and World Health Organization. Philippines Health Service Delivery Profile 2012 [Online]. 2012 [Accessed 12 Feb 2015]. Available from wpro.who.int/health_services/service_delivery_ profile_philippines.pdf.

4. Montenegro, H., E Levcovitz, R Holder, J Ruales, J Suarez. Integrated Health Service Delivery Networks: Concepts, Policy Options and a Road Map for Implementation in the Americas. Washington, D.C.: Pan American Health Organization, 2011.

5. World Health Organization. Health Services and Readiness Assessment: The SARA Methodology [Online]. [Accessed 15 Nov 2014] Available from http://www.who.int/healthinfo/systems/sara_ indicators_questionnaire/en/.

6. Navotas City Health Office. Socio-economic profile [Online]. 2010 [Accessed 15 Nov 2014]. Available from http://www.navotas.gov.ph/ Downloads/MAYOR/Socio-Economic\%20Profile\%202010.pdf.
7. Cawayan Local Government Unit. Facts and Figures [Online]. [Accessed 15 Nov 2014]. Available from http://lgucawayanmasbate. com/lgu-profile/2-basic-facts-and-figures.

8. Panizal, R. Navotas opens first hospital on November 21 [Online]. 2014 [Accessed 08 Mar 2017]. Available from http://www.remate. $\mathrm{ph} / 2014 / 11 /$ navotas-opens-first-hospital-on-november-21/.

9. Republic of the Philippines. Republic Act 256. An Act Establishing a Ten-Bed Capacity Municipal Hospital in the Municipality of Cawayan, Province of Masbate, to be Known as the Cawayan District Hospital, and Appropriation Funds Therefor. 1982.

10. Department of Health. Philippine Health Agenda 2016-2022 [Online]. 2016 [Accessed 20 Jan 2017]. Available from http://www. doh.gov.ph/sites/default/files/basic-page/Philippine\%20Health\%20 Agenda_Dec1_1.pdf.

11. World Health Organization. What are the latest statistics on health workforce availability? Why does the latest HRH report (A Universal Truth - No health without a Workforce, 2013) use a different threshold (33.45/10'000) from the WHO 2006 report (22.8/10'000)? [Online] 2005 [Accessed 9 Nov 2014]. Available from http://www.who.int/ workforcealliance/media/qa/05/en/.

12. Patouillard E, Goodman CA, Hanson KG, Mills AJ. Can working with the private for-profit sector improve utilization of quality health services by the poor? A systematic review of the literature. International Journal for Equity in Health. 2007;6(17). 